\title{
Management of Sustainability, Its Measurement and Relevance in the Enterprise
}

\section{Patrícia JÁNOŠOVÁ*and Emese TOKARČÍKOVÁ}

University of Žilina, Žilina, Slovakia; Patricia.Janosova@fri.uniza.sk, Emese.Tokarcikova@fri.uniza.sk

* Corresponding author: Patricia.Janosova@fri.uniza.sk

\begin{abstract}
The commitment of the enterprise to act in a sustainable way requires decisionmaking based on an appropriate set of sustainability indicators. The current knowledge about sustainability offers numerous indicators and best practices. However, not all indicators are verified in practice and implementable for every enterprise. The article deals with the results of our survey in conditions of Slovak business environment, which showing a disproportion of the numbers and types of recorded sustainability metrics in practices. This causes a question that despite of the fact, that sustainability measurement requires a holistic approach, whether the selected set of sustainability indicators efficient to fulfill the given enterprise's and its stakeholders' needs. Based on we are offering a suggestion how to create a basic priority for this multicriterial choice problem. Setting up the main criteria and their multilateral relations improving management of choosing appropriate measurement and its relevance for the given enterprise. In our opinion, the most effective way is to create a framework of indicators for each of the business sectors.
\end{abstract}

Keywords: sustainability; management; indicators; decision making; measurement

JEL Classification: Q01; M00; L00

\section{Introduction}

Economic theory teaches us that the main goal of all enterprises is to maximize their profits. However, in the world with limited sources (factors of production) to focus solely only to profit generation is no more enough. This one-sided orientation of the management does not bring long-term sustainability and certainty of successful business activities of the enterprise. Due this reason behind increasing social pressures also the business environment is changing. Enterprises are more and more engaging in interactions with their stakeholders, their corporate strategies are affected by the social and environmental impact of their business.

Our article firstly describes the result of our survey focused on the perception of sustainability issues by Slovak enterprises with analysis what type of sustainability indicators they prefer in their measurement and reporting. Based on literate review and the findings of our survey, we discuss and make suggestions for managers, how to orient and choose appropriate set sustainability indicators and metrics. Why? Sustainability from our point of view cannot be just a matter of enterprise' marketing or making only a good impression.

As a definition says sustainability means "meeting our own needs without compromising the ability of future generation to meet their own needs" (Brundtland report, 
1987), so measurement of indicators should be tailored for a specific business sector and their current and future stakeholders to ensure lasting prosperity. Sustainability indicator, according to our understanding and relevant to performance measurement, is a summary measure that informs managers on the stage of, or change in, the business environment that is being measured. Following, the metric is the measured value(s) used to assets specific indicators, which defines the units and how indicators is being measured. In case of quantifiable sustainability goals and their respective indicators enable the systematic tracking of set sustainability targets and guiding sustainability trajectories (Lutje \& Wohlgemuth, 2020). Our understanding is based on scientific theories and practice where researchers prefer two basic ways of understanding the purpose of sustainability indicators. The first way is that sustainability indicators are "data carriers" so measures entities whose identity exclusively relies on the variables and parameters whit which they associated, independently from the context, purpose, and logistics behind their use (Elgert, 2018; Gudmundsson, 2003). The second way is that sustainability indicators are a "message carriers", so they are arguments, ideas, and expectations that particular actors mobilize regarding sustainability issues. (Lehtonen et al. 2016, Kates et al., 2005).

\subsection{Literature Review}

The Directive 2014/95/EU requires large enterprises (those that have 500+ employees operating in the EU and are public interest entities) "to disclose relevant non- financial information to provide investors and other stakeholders with a more complete picture of their development, performance and position and the impact of their activity. (Directive 2014/95/EU, 2014). Another publication, such as UN Global Compact GRI Guideline is the basic key framework of sustainability reporting since the late 1990s. The vision of these pioneers is to push every organization to adapt sustainability forms as an essential part of their strategies, plans, and business activities. UN Global Compact with Agenda 2030 explaining through 17 Sustainable Development Goals how business leaders could act towards sustainability and decrease the disparities between countries (Inescu et al., 2018; Strakova et al., 2016). According to Verboven and Vanherck (2016), the objectives of AGENDA 2030 are designed to be applicable in both developing and developed countries. The objectives of AGENDA 2030 contain a total of 230 indicators, and due to the difficulty of recording them, each country in the world must choose those indicators that are characteristic of it. In this context, we see unexplored potential for defining indicators of sustainable development, which will be characteristic of business sectors and has not yet been developed.

Surveys, like research paper based on correlation analysis by Socolius et al. (2018) show that the acceptance of the enterprise' management in terms of the sustainable development is in a close relationship with implementing voluntary reporting and the willingness to increase sustainability activities."

Sustainability indicators recommended by authorities help not only for managers, but also for researchers to measure the enterprise ' business involvement in sustainable activities, to help to identify business opportunities, strengthen trust and above all, to increase employee motivation. Ejarque and Campos (2020) in their study confirm that a focus on 
sustainability in the enterprise is essential. They also state that the literature offers several frameworks to support the implementation of sustainable elements in the enterprise, but empirical evidence in this area is still lacking and the presented frameworks are not verified.

Indicators related to the human and social sustainability measure a maintenance and improvement of the human capital investments and promote business values that respect human capital. Kucharcikova and Miciak (2018) as well Vetrakova et al. (2018) offers verified metrics and approaches for the assessment of how effectively the enterprise uses human capital. Expert teams leaded by and Lorincova et al. (2018) explaining how indicators about employee's motivation, in terms of occupation classification and age, as a managerial tool can be used for approximation of employees 'needs with enterprise goals.

Environmental sustainability indicators are measuring how enterprise minimize negative impact (externalities) of own business activities on the environment. EMS standards were created on the strict legislative requirements, but unfortunately sometimes was considered cost rather than a resource or opportunity. Evaluation of environmental indicators also leads to suggest how to implement complex control quality management not only in enterprises, but even in organization like it is shown by Tomaskinova et al. (2013). Ecological footprint is a frequently used environmental indicator identifying the reduction potential of the enterprise (Costa et al., 2019).

Future economic equity and fairness could be achieved with strong and stable economy built on the innovation and investments. Better use of resources and economic impacts of describing performance from different stakeholders' perspective might involve a conceptual and practical attitude building a bridge between them and enterprise own financial performance (Malichová \& Durisova, 2015). Decision making based on knowledge about economic performance indicators directly impacts enterprises 'ability to maintain a sustainable long-term business and to distribute wealth. (Malichová \& Miciak, 2019).

Although in some cases, sustainability indicators may overlap, it is important to identify which specific set of them is unique for selected enterprise and make a decision, how their measurements and reporting to effectively incorporate it on the operative and strategic level of the management.

\section{Methodology}

As part of the paper aimed at identifying indicators of sustainable development in enterprises in the Slovak Republic, we have initially identified the following research questions:

- Which specific indicators in the enterprise does the management consider to be the most important?

- What types of indicators based on the triple bottom line model are recorded in the enterprise?

- Which types of indicators based on the triple bottom line model have the highest incidence in enterprises?

Our paper focused holistically on identifying indicators of sustainable development in enterprises in the Slovak Republic. Respondents introduced us to the main indicators that they record in the enterprise and which are of great importance to them. In some cases, these 
were activities in which the extent of action was recorded. The total number of enterprises that participated in the paper was 79. Based on size, they are specified as follows: Micro - 4, Small -29, Medium-sized 24, Large -22, Total -79.

\section{Results}

We divided the achieved results and specific indicators applied in enterprises on the basis of the triple bottom line model. We found that out of the total number of indicators, $56 \%$ of indicators were of an environmental nature, $33 \%$ of indicators were of a social nature and only $11 \%$ were of an economic nature (Figure 1 and Figure 2). When determining economic indicators, we often encounter the problem of public reporting and measurement. This is due to the fact that enterprises are obliged to record most economic indicators due to legislation. Therefore, it is difficult to determine which economic indicators are reported by enterprises in accordance with sustainable development.

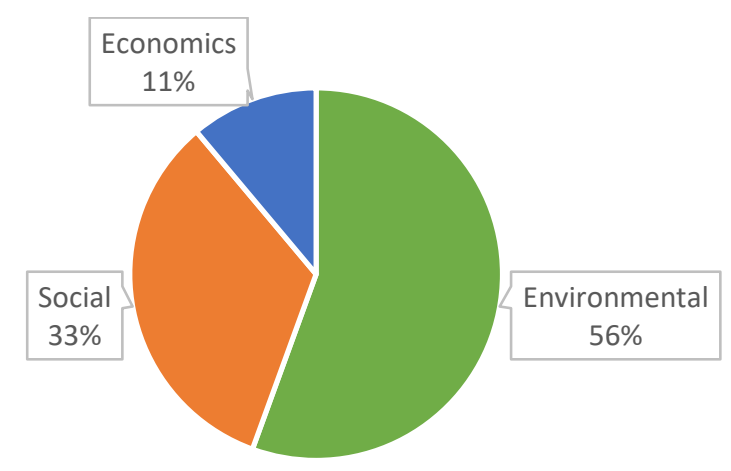

Figure 1. Variety of indicators based on the triple bottom line model. (own survey, 2020)

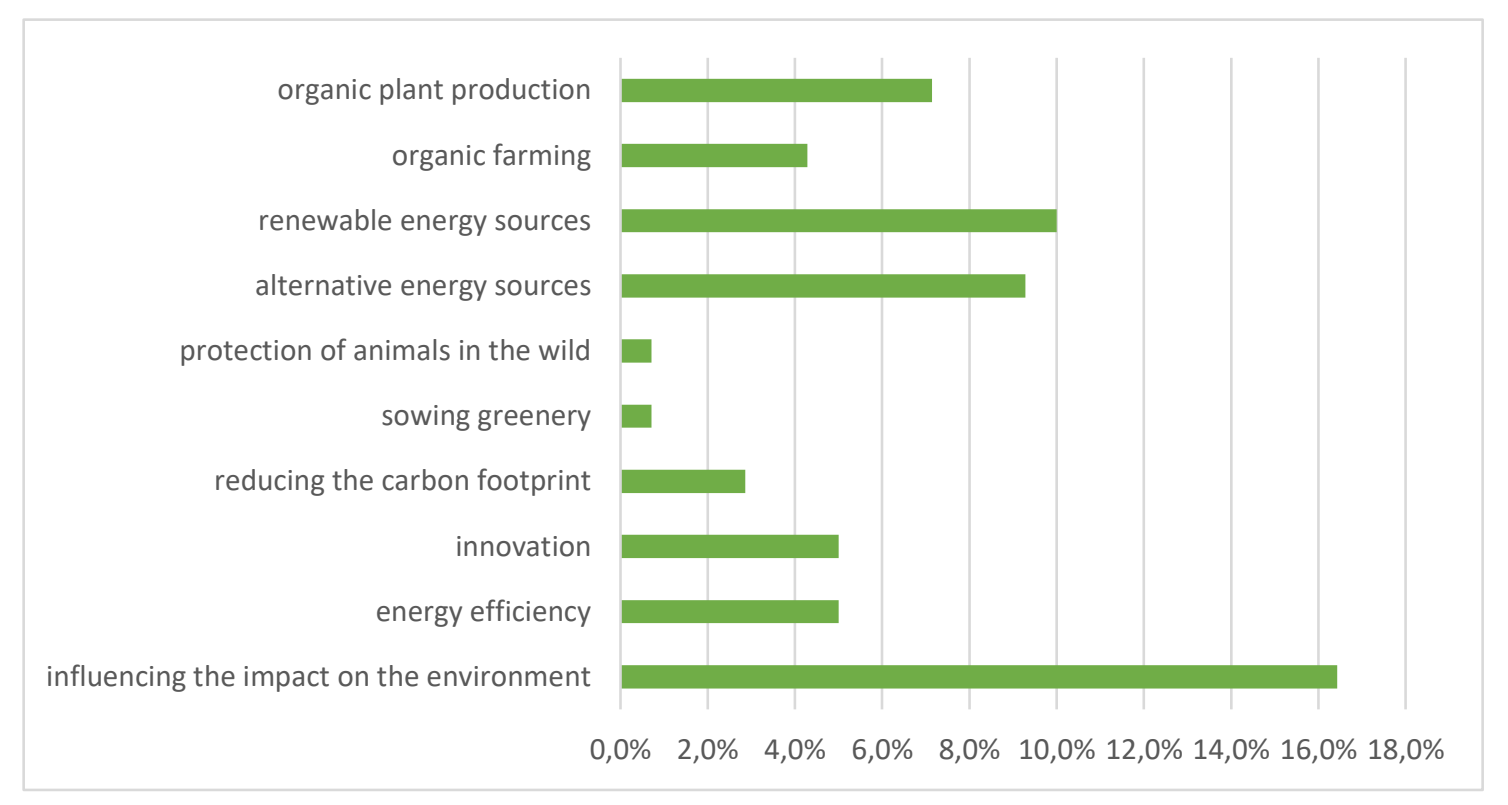

Figure 2. Proportion of environmental indicators during measurement (own survey, 2020)

In terms of environmental indicators, the highest incidence is recorded in the enterprise's focus on influencing the enterprise's impact on the environment (16.4\%), the use of renewable 
energy sources (10\%) and alternative energy sources (9.3\%). By their nature, these important indicators fall within the objectives of the UN program called AGENDA 2030.

When determining social indicators (Figure 3) the focus on employee development was the most represented (12.1\%). It is very important for the management of the enterprise to develop the potential of employees, motivate them at work and focus on their satisfaction and responsibility. In the second place in the occurrence of social indicators, the protection of employees' health occurred (8.6\%). The enterprise's management takes care of the health and safety of its employees, but also their health outside work. In every enterprise, it is essential that the workforce is loyal to the enterprise, while it is necessary to pay attention to the health and satisfaction of employees. In the third place with the highest frequency of occurrence is a significant influence of stakeholders.

The term broadly covers a range of groups, namely: suppliers, customers, employees, management, shareholders, associations, trade unions, politicians, regional and state representatives. In most cases, the enterprise's management itself pointed out that it is the stakeholders who have a significant internal and external influence on the enterprise's activities. Therefore, focusing on their business impact is essential.

The indicators represented in the lowest number include provided benefits for employees $(5.7 \%)$, community support $(2.1 \%)$ and cooperation with sheltered workshops $(0.7 \%)$. It is a priority for the employer to employ skilled, responsible, and loyal employees. Employee benefits are currently the second most important reason when choosing a job or staying in employment in Slovakia. One of the increasingly popular forms of providing employee benefits is currently the "cafeteria system".

Community support, in which we advise education, sports activities and other activities for the development of citizens, has always been one of the popular forms of support from businesses. Thanks to them, the enterprise builds a good name and uses them as a suitable form of marketing. Cooperation with sheltered workshops in Slovakia is carried out only to a very small extent (Figure 3).

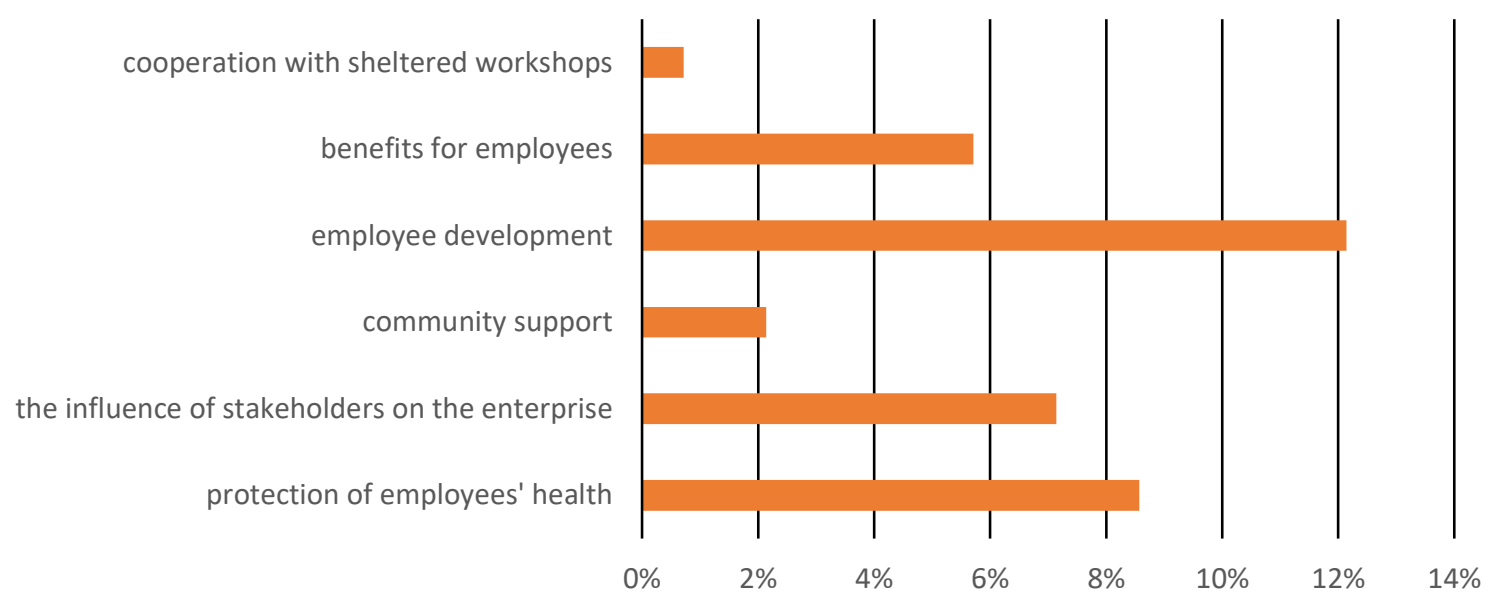

Figure 3. Proportion of social indicators during the measurement. (own survey, 2020) 
Finally, if we divide all the indicators that we recorded during the research, according to the triple bottom line model, we get the following Figure 4.

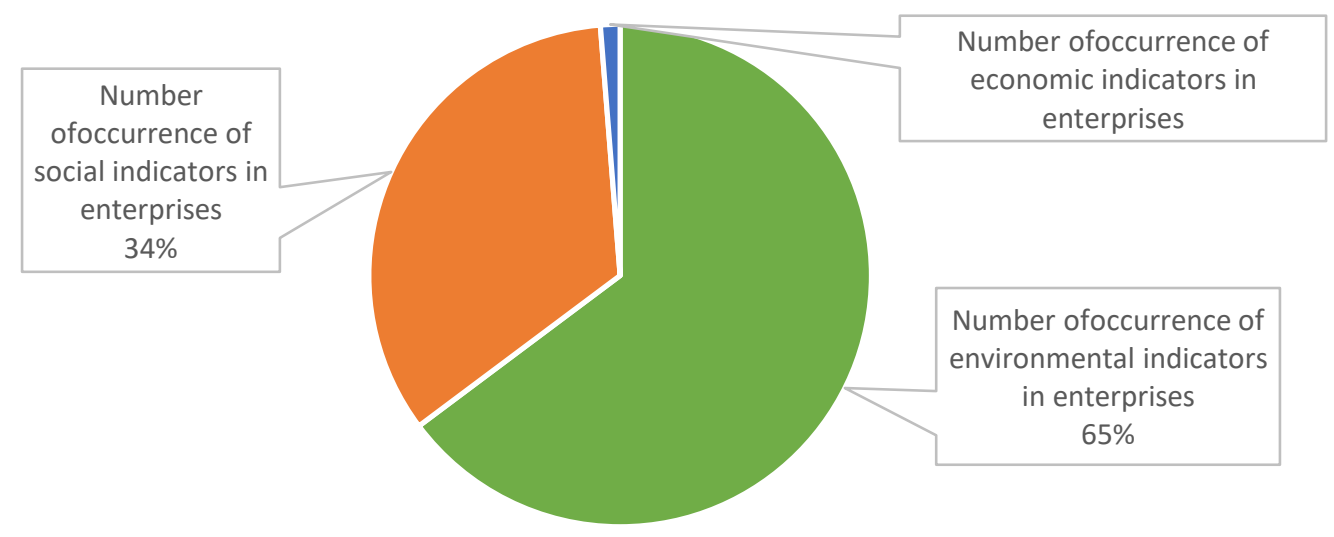

Figure 4. Total share of sustainability indicators measured in enterprises. (own survey, 2020)

As many as $65 \%$ of all indicators have an environmental character, $34 \%$ have a social character and only $1 \%$ show indicators of an economic nature. The ratio of indicators from our research based on the triple bottom line is therefore 65: 34: 1, while the ratio of indicators based on GRI reporting (G3 guideline) from the perspective of the triple bottom line is 38:51:11.

\section{Discussion}

More and more enterprises disclosure sustainability reports or social balance reports to communicate their progress towards achievement sustainability goals. They usually use GRI Standards and trying to offer a complete holistic picture of all their sustainability issues and activities, but

- Is it possible to be in every area (Economy, Society, Environment) successful?

- What about enterprises who are just starting with their efforts towards sustainability?

- Where must they start?

Our personal interviews with managers cooperated on our survey showed us, that there is an existing need to find appropriate way which set of indicators is suitable for measurement resp. reporting and linking structurally, conceptual, and chronologically to improve the decision-making process in a certain enterprise.

This is a multicriterial decision choice problem which requires to design a decision making model based on understanding and analyzing a current situation and enterprise needs. Certainly, aspects can evaluate conflicting criteria in decision making, but also some aspects for given enterprise are irrelevant. Our suggestions there are focused on further aspects of multicriterial decision-making process how to choose appropriate sustainability indicators for their own enterprise (Figure 5). 
Basic theoretical background to achieve sustainability goals:

TRIPLE BOTTON LINE - $3 P$ ECONOMIC, ENVIROMENTAL, SOCIAL

AGENDA 2030 (UN Global Compact)

17 SDGs

Achieving sustainability goals related with:

\begin{tabular}{|c|c|c|c|c|c|}
\hline FACTORS OF & BUSINESS & STAKEHOLDERS ' & PROCES OF & BUSINESS & LAW \& \\
\hline PRODUCTION & ORIENTATION & NEEDS \& PROSPECT & PRODUCTION & CONDITION & REGULATION \\
\hline
\end{tabular}

Quantitative and qualitative sustainable indicators:
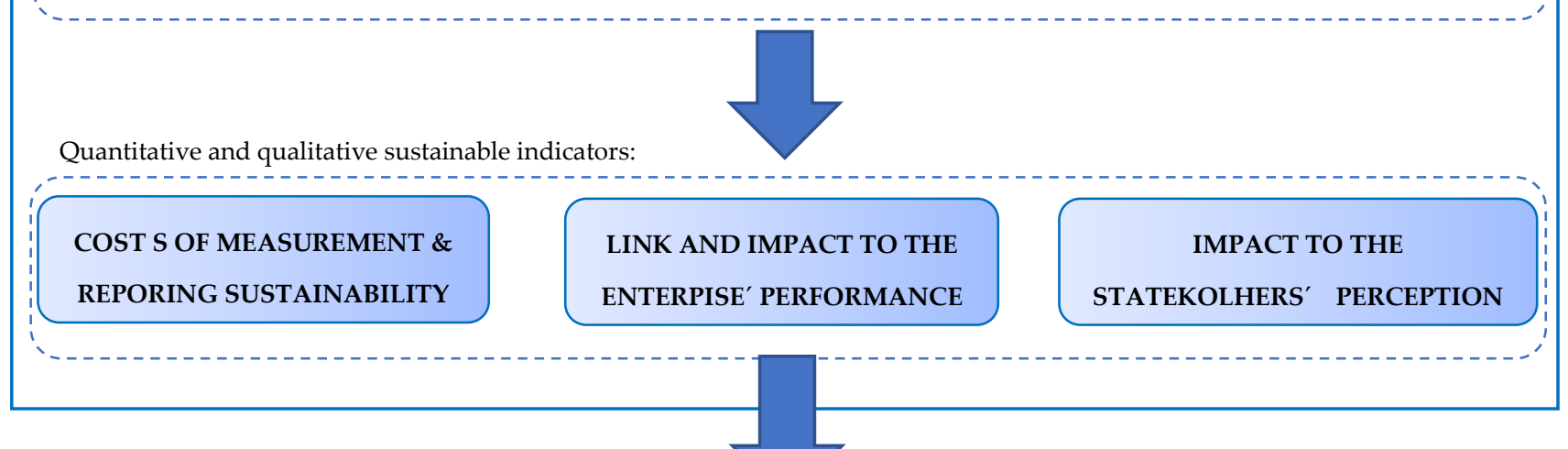

Activities related with choosing sustainable indicators:

\section{MANAGEMENT OF SET OF}

SUSTAINABILITY INDICATORS

MEASUREMENT

\section{REPORTING}

Figure 5. Set of aspects for multicriterial decision making how to choose sustainability indicators for given enterprise.

1. aspect: Which theory allows for managers to capture and implement activities leading to sustainability more precisely for their concrete enterprise and offer them also to improve business performance? Is it enough to be guided by theory of triple bottom line and stakeholder 'theories, or managers should be following more detailed UN 's 17 SDGs? How to choose criteria which topic of sustainability are should be prioritized by the enterprise?

2. aspect: The answers the above questions managers of a selected enterprise can find by comparation of activities towards sustainability to:

- Sources (Factors of production) needed for the production process (as well in case of provision of services) and further business model of the enterprise. 
- Business orientation of the enterprise with regard i.e., sector of where operates, the size of the market, competition ability, existing laws \& regulations, type, and characteristics of produced product or provided service, etc.

- Stakeholders needs and prospect - to be focused on the importance of anyone directly or indirectly involved by internal and external surroundings of production or provision of services or broader stakeholders (Benn et al., 2014).

3. aspect: Certainly, acting in a sustainable way, also measurement and reporting sustainability indicators generates costs. (Durisova \& Kucharcikova, 2014) In a business context, managers want to refer the efficient use of assets to maintain enterprise profitability over time. Usage of modern business performance evaluation methods is helpful, but not always lead same results. Hence, researchers warn to check them every time, which of them are suitable for measuring and to create a performance portfolio (ranking) (Onuferova et al., 2020). In a sustainability context the measurement of impact to the stakeholder 's perception, indeed brings out additional costs, is essential to know which indicators are worth to measure and report and how to use i.e., ICT to decrease these costs. Software support in praxis and the significance of dashboards for decision process in the enterprises provide views of key performance indicators (Teplická et al., 2020), and also knowledge of social network usage (Cenková \& Steingartner, 2020) and create a base for competitiveness. Subsequently relationship binding of environmental, social and governance scores and sustainability performance can assign priorities how to implement sustainability into the enterprise strategies and practice. (Rajesh \& Rajendran, 2020)

4 aspect: This aspect summarizes the managerial activities vice-versa affected by choosing the appropriate unique set of the sustainability indicators for selected enterprise. In case of measurement manager should be capable quantify the enterprise ' value to the stakeholders, which is central for purpose -driven leadership approach and decision making process. This sustainable evaluation can use i.e., grey-based approach, used by Agrawal and Vinodh (2019) or multiple attribute decision making tools like shown by Ecer et al. (2019) or De Steur et al. (2019), etc.

\section{Conclusions}

Sustainability requires a holistic approach to the enterprise's activities and needs. For this reason, the fulfillment of sustainability goals is very complex and demanding process even in small enterprise. Managers in their decision-making process should deal with the multicriterial choice problem of what to prioritize. We are convinced, that managers must also deal with analysis and effects, which can be through series of sustainability indicators reflected in enterprise's sustainability engagements and also enterprise's performance. The presented survey conducted in 79 enterprises in Slovakia provided us with a picture of the situation of recording indicators of sustainable development in practice. Each of the enterprise is characterized by different indicators that need to be recorded. The survey shows that enterprises generally focus mainly on addressing environmental issues. This is a consequence of managers' awareness of the need to protect the environment. This is mainly 
due to the need to maintain a healthy environment for the next generations of people, animals, and plants on the planet. Our future research therefore will be specified to develop sector-specific environmental indicators. The reason is the need to focus on those indicators that significantly affect the environment and their recording is highly justified.

Acknowledgments: This work was supported by Grant System of University of Zilina No. 8058/2020. Creating a system of relevant indicators of sustainable business development for effective business management.

\section{References}

Agrawal, R., \& Vinodh, S. (2020). Sustainability evaluation of additive manufacturing processes using greybased approach. Grey Systems: Theory and Application, 10(4), 393-412. https://doi.org/10.1108/GS-08-2019-0028

Benn, S., Dunphy, D., \& Griffiths, A. (2014) Organizational change for corporate sustainability. Routledge, Oxford.

Brundtland report. (1987). Our Common Future: Report of the World Commission on Environment and Development. UN Documents. https://sustainabledevelopment.un.org/content/documents/ 5987our-common-future.pdf

Cenková, R., \& Steingartner, W. (2020), Use of internet social networks in academic. Journal of Information and Organizational Sciences, 44(2), 275-295.

Costa, I., Martins, F. G., \& Alves, I. (2019). Ecological Footprint as a Sustainability indicator to analyze energy consumption in a Portuguese textile facility. International Journal of Energy and Environmental Engineering. 10(4), 523-528, https://doi.org/10.1007/s40095-018-0268-6

Directive 2014/95/EU. Disclosure of non-financial and diversity information by large companies and groups Sustainability/Corporate Social Responsibility (CSR)and the European Union. European Union, The European Parliament and The Council of the European Union. http://eur-lex.europa.eu/legalcontent/EN/LSU/?uri=CELEX:32014L0095

DeSteur, H., Temmerman, H., Gellznch, X., \& Canavari, M. (2019). Drivers, adoption, and evaluation of sustainability practice in Italian wine SMEs. Business Strategy and Environment 29(2), 744-762. https://doi.org/10.1002/bse.2436

Durisova, M., \& Kucharcikova, A. (2014). The Quantitative Expression of Factors which Affect the Cost of Transport Enterprise. In 18th International Conference on Transport Means 2014 (pp. 190-193). Kaunas Univ Technol, Kaunas, Lithuania.

Ecer, F., Pamucar, D., Zolfani, S. H., \& Eshkalag, M. K. (2019). Sustainability assessment of OPEC countries: Application of a multiple attribute decision making tool. Journal of Cleaner Production, 241. https://doi.org/10.1016/j.jclepro.2019.118324

Ejarque, A. T., \& Campos, V. (2020). Assessing the Economy for the Common Good Measurement Theory Ability to Integrate the SDGs into MSMEs. Sustainability, 12(24). https://doi.org/10.3390/su122410305

Elgert, L. (2018). Rating the sustainable city: 'Measurementality', transparency, and un-expected outcomes at the knowledge-policy interface. Environmental Science. Policy 79, 16-24. https://doi.org/10.1016/j.envsci.2017.10.006

Gudmundsson, H. (2003). The policy use of environmental indicators -learning from evaluation research. Journal of Transdisciplinary Environmental Studies, 2(2), 1-12.

Inescu, R. V., Zlati, M. L., Antohi, V.M., \& Stanciu, S. (2018). Reduced Inequalities as Factor of Sustainable Development: The Analysis Under Econometric Models. Sustainability, 10(10). https://doi.org/10.3390/su10103523

Kates, R. W., Parris, T. M., \& Leiserowitz, A. A. (2005). What is sustainable development? Goals, indicators, values, and practice. Environ.: Sci. Policy Sustain. Dev. 47(3), 8-21.

Kucharcikova, A., \& Miciak, M. (2018). Human Capital Management in transport Enterprises with the Acceptance of Sustainable Development in the Slovak Republic. Sustainability, 10(7). https://doi.org/10.3390/su10072530

Lehtonen, M., Sébastien, L., \& Bauler, T. (2016). The multiple roles of sustainability indicators in informational governance: between intended use and unanticipated in-fluence. Current Opinion in Environmental Sustainability, 18, 1-9. https://doi.org/10.1016/j.cosust.2015.05.009

Lutje, A., \& Wohlgemuth, V. (2020). Tracking Sustainability Targets with Quantitative Indicator Systems for Performance Measurement of Industrial Symbiosis in Industrial Parks. Administrative Science, 10(1). https://doi.org/10.3390/admsci10010003 
Lorincova, S., Hitka, M., Starchon, P., \& Stachova, K. (2018). Strategic Instrument for Sustainability of Human Resource Management in Small and Medium-Sized Enterprises Using Management Data. Sustainability, 10(10). https://doi.org/10.3390/su10103687

Malichova, E., \& Durisova, M. (2015). Evaluation of Financial Performance of Enterprises in IT Sector. In 9th International Scientific Conference on Business Economics and Management (BEM) (vol. 34, pp. 238-243). Tech Univ Zvolen. Procedia Economics and Finance.

Malichova, E., \& Miciak, M. (2019). The Model of Managerial Decision - making on Investment in Medium sized In 17th International Scientific Conference Hradec Economic Days (vol. 9, pp. 45-56). University of Hradec Kralove.

Onuferova, E., Cabinova, V., \& Vargova, T. D. (2020). Analysis of modern methods for increasing and managing the financial prosperity of businesses in the context of performance: a case study of the tourism sector in Slovakia. OECONOMIA COPERNICANA, 11(1), 95-116. https://doi.org/10.24136/oc.2020.004

Rajesh, R., \& Rajendran, C. (2020). Relating Environmental, Social and Governance score and sustainability performances of firms: An empirical analysis. Business Strategy and the Environment, 29(3), 1247-1267. https://doi.org/10.1002/bse.2429

Socolius, M., Grosu, V., Hlaciuc, E., \& Stanciu, S. (2018). Analysis of Social Responsibility and Reporting Methods of Romanian Companies in the Countries of the European Union. Sustainability, 10(12). https://doi.org/10.3390/su10124662

Strakova, J., Kucharcikova, A., Partlova, P., \& Vachal, J. (2016). Foreign Direct Investment and Transport Serviceability - a Prerequisite for the Development and Stability of National and Regional Economies. NASE MORE, 63(3), 204-210. https://doi.org/10.17818/NM/2016/SI24

Teplická, K., Steingartner, W., Kadárová, J., \& Hurná, S. (2020). Dashboards - effective instrument of decision in synergy with software support. Polish Journal of Management Studies, 22(1), 565-582. https://doi.org/10.17512/pjms.2020.22.1.36

Tomaskinova, J., Tomaskin, J., \& Rakalova, M. (2013) Management of Sustainable development of schools by evaluation of file indicators of sustainable development of school. In $7^{\text {th }}$ International Technology, Education and Development conference (INTED 2013) (pp. 4791-1795). INTED Proceedings, Valencia.

United Nation Global Compact. Sustainable Development Goals 2030 - SDGs. https://www.unglobalcompact.org/sdgs

Verboven, H., \& Vanherck, L. (2016). Sustainability management of SMEs and the UN Sustainable Development Goals. Uwf UmweltWirtschaftsForum, 24(2-3), 165-178. https://doi.org/10.1007/s00550-016-0407-6

Vetrakova, M., Hitka, M., Potkany, M., Lorincova, S., \& Smerek, L. (2018) Corporate Sustainability in the Process of Employee Recruitment through Social Networks in Conditions of Slovak Small and Medium Enterprises. Sustainability, 10(5). https://doi.org/10.3390/su10051670 